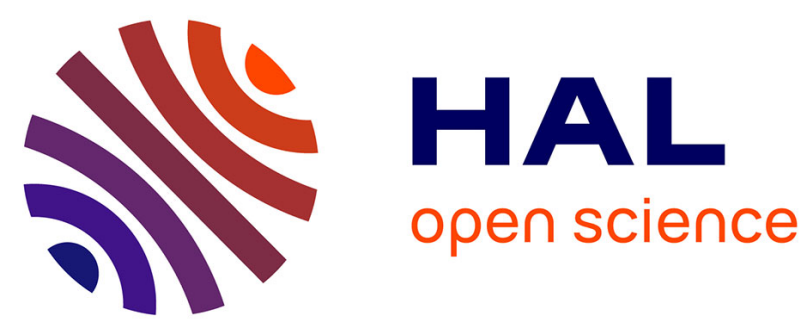

\title{
Phthalates and alkylphenols in industrial and domestic effluents: Case of Paris conurbation (France)
}

A. Bergé, J. Gasperi, V. Rocher, L. Gras, A. Coursimault, R. Moilleron

\section{To cite this version:}

A. Bergé, J. Gasperi, V. Rocher, L. Gras, A. Coursimault, et al.. Phthalates and alkylphenols in industrial and domestic effluents: Case of Paris conurbation (France). Science of the Total Environment, 2014, 488-489 (1), pp.26-35. 10.1016/j.scitotenv.2014.04.081 . hal-01238367

\section{HAL Id: hal-01238367 \\ https://hal-enpc.archives-ouvertes.fr/hal-01238367}

Submitted on 23 May 2018

HAL is a multi-disciplinary open access archive for the deposit and dissemination of scientific research documents, whether they are published or not. The documents may come from teaching and research institutions in France or abroad, or from public or private research centers.
L'archive ouverte pluridisciplinaire HAL, est destinée au dépôt et à la diffusion de documents scientifiques de niveau recherche, publiés ou non, émanant des établissements d'enseignement et de recherche français ou étrangers, des laboratoires publics ou privés. 


\title{
PHTHALATES AND ALKYLPHENOLS IN INDUSTRIAL AND DOMESTIC EFFLUENTS: CASE OF PARIS CONURBATION (FRANCE)
}

\author{
A. BERGÉ ${ }^{(1,2)}$, J. GASPERI $^{(2)}$, V. ROCHER ${ }^{(3)}$, L. GRAS $^{(4)}$, A. COURSIMAULT ${ }^{(1)}$, R. $^{2}$ \\ MOILLERON ${ }^{\left(2^{*}\right)}$ \\ (1) Laboratoire Central de la Préfecture de Police, 39 bis rue Dantzig, 75015 Paris, France \\ (2) Leesu (UMR MA-102), Université Paris-Est, AgroParisTech, 61 avenue du Général de Gaulle, 94010 \\ Créteil Cedex, France - e-mail: moilleron@u-pec.fr \\ (3) SIAAP, Direction du Développement et de la Prospective, 82 avenue Kléber, 92070 Colombes, \\ France \\ (4) SEVESC, 15 - 19 quai Gallieni, 92150 Suresnes, France \\ * Corresponding author
}

\begin{abstract}
Phthalates and alkylphenols are toxics classified as endocrine disrupting compounds (EDCs). They are of particular concern due to their ubiquity and generally higher levels found in the environment comparatively to other EDCs. Industrial and domestic discharges might affect the quality of receiving waters by discharging organic matter and contaminants through treated waters and combined sewer overflows. Historically, industrial discharges are often considered as the principal vector of pollution in urban areas. If this observation was true in the past for some contaminants, no current data are today available to compare the quality of industrial and domestic discharges as regard EDCs. In this context, a total of 45 domestic samples as well as 101 industrial samples were collected from different sites, including 14 residential and 33 industrial facilities. This study focuses more specifically on 4 phthalates and 2 alkylphenols, among the most commonly studied congeners. A particular attention was also given to routine wastewater quality parameters. For most substances, wastewaters from the different sites were heavily contaminated; they display concentrations up to $1,200 \mu \mathrm{g} / \mathrm{l}$ for di-(2-etylhexyl) phthalate (DEHP) and between 10 to $100 \mu \mathrm{g} / \mathrm{l}$ for diethyl phthalate (DEP) and nonylphenol (NP). Overall, for the majority of compounds, the industrial contribution to the flux of contaminant reaching the wastewater treatment plants range between 1 and 3\%. The data generated during this work constitutes one of the first studies conducted in Europe on industrial fluxes for a variety of sectors of activity. The study of the wastewater contribution was used to better predict both the industrial and domestic contributions at the scale of a huge conurbation heavily urbanized but with a weak industrial cover, illustrated by the case of Paris. Our results indicate that specific investigations on domestic discharges are necessary in order to reduce the release of phthalates and alkylphenols in the sewer systems for such conurbations.
\end{abstract}

\section{KEYWORDS}

Phthalates, alkylphenols, industrial wastewater, domestic wastewater, industrial contribution, industrial loads, EDC

\section{INTRODUCTION}

The adoption and the implementation of the European Water Framework Directive (EU 2000) have led to establishing targeted objectives for reaching the good ecological and chemical status for European water bodies (groundwater, surface water and marine waters up to one nautical mile from shore) by 2015,2017 or 2020 depending on the initial quality of waters. A list of 33 priority substances has been 
regulated in the Decision 2455/2001/EC (EU 2001) and a number of specific "daughter" directives by defining emission limit values and quality objectives in water bodies, namely surface and coastal waters, for member states. In order to identify substances that could represent an important risk to the environment, their concentrations are compared to Environmental Quality Standards (EU 2008). Over the last three decades, a large number of studies have highlighted several classes of hazardous substances, classified as "endocrine-disrupting compounds" (EDC) (Lund 2000, Purdom et al. 1994). Among the more frequently mentioned EDCs (e.g., PCBs, pesticides and more recently estrogenic hormones), phthalates and alkylphenols are of particular concern due to their ubiquity and to higher levels found in the environment comparatively to other EDCs (Bergé et al. 2013, 2012a, Peijnenburg and Struijs 2006, Sanchez-Avila et al. 2009, Vethaak et al. 2005). Phthalates are widely used in many industrial and household applications such as adhesives, paints, inks, rubbers, surface treatment, etc. (Lassen et al. 2009). In addition, they were massively used in the composition of polyvinyl chloride (PVC) and other resins for polymers because of the stability, fluidity and low volatility of heavier congeners (Fountoulakis et al. 2006). Xie et al. (2007) reported that approximately 6,000,000 tons per year are produced throughout the world, this production has remained quite constant for the last 20 years. Alkylphenols are non-ionic surfactants extensively used as additives in detergents and in the production of alkylphenol ethoxylates. These substances have been used in a wide range of applications such as cosmetics, personal care-products, cleaning agents, paints, solubilisers, etc. (Ying et al. 2002). Additionally, alkylphenols have mainly derived from the biodegradation of long chain ethoxylates that lead to their continuous diffusion in environmental media (Giger et al. 2009, John and White 1998).

Though the data collected in the natural environment begin to be substantial, especially for alkylphenols and to a lower extent for phthalates, information on the sources of contamination (industrial and domestic wastewaters, discharges from wastewater treatment plants, combined sewer overflows, etc.) are still too limited to define priority actions to reduce efficiently their dissemination in both urban and natural environments (Bergé et al. 2012a). Among these sources, industrial discharges are often considered as principal vector of pollution in urban areas. Nowadays, and as demonstrated by two metaanalysis on alkylphenols, and phthalates (Bergé et al. 2013, 2012a), studies on industrial contributions 
are extremely limited. To date, only 4-5 papers are dealing with quality of industrial discharges as regards alkylphenols (AP) and phthalic acid esters (PAE). Furthermore, few data are available on the contamination levels of hazardous substances in purely domestic wastewater ( $n=4$; (Bergé et al. 2013, 2012a)). Finally, if various studies identify wastewater treatment plant (WWTP) effluents as sources of EDCs in surface waters (Harrison et al. 2006, Pryor et al. 2002), none of them dealt with i) the phthalate and alkylphenol origins and sources in wastewater upstream catchment, ii) the quality of industrial discharges comparatively to domestic discharges and iii) the contributions of industrial effluents to the wastewater contamination at an urban scale.

This work as part of the French research program "Observatory of Urban Pollutants" (OPUR) was performed in collaboration between the Central Laboratory of the Police Department of Paris (LCPP), the Laboratory of Water, Environment and Urban Systems (LEESU), the Water Society of Versailles and Saint-Cloud (SEVESC) and the interdepartmental association for sewage in Paris conurbation (SIAAP). This work performed at the scale of the Paris conurbation consolidates an action conducted by the French organization INERIS, at both the regional and national scales, in order to research and to reduce the release of hazardous substances into the environment (3RSDE program). This study aimed (i) at improving knowledge on the contaminations of both industrial and domestic effluents for wastewater routine quality parameters, phthalates, and alkylphenols by collecting a substantial dataset and (ii) at establishing industrial mass fluxes and their contribution to pollution transported within the sewerage systems at the scale of an important agglomeration. This study focuses more specifically on four phthalates and two alkylphenols: diethyl phthalate (DEP), di-n-butyl phthalate (DnBP), butylbenzyl phthalate (BBP), di-(2-etylhexyl) phthalate (DEHP), nonylphenol (NP) and octylphenol (OP). In the case of classified installations, most of industrial sites are subjected to authorizations for discharging into the sewer network. Such authorizations establish a framework for targeting pollution source control. For instance, the limit value for Chemical Oxygen Demand (COD) has been fixed to 2,000 $\mathrm{mg} \mathrm{O}_{2} / \mathrm{l}$ for classified installations according to the sanitary regulation of the Parisian conurbation, whose recommendations are very similar to those of the EU urban wastewater directive.

\section{MATERIALS AND METHODS}

\subsection{Sites and sampling strategy}


Industrial and domestic wastewater samples were collected within the Paris conurbation catchment (Paris intra-muros and its suburbs). The effluents from eleven main industrial activities in Paris conurbation were considered in this study; these activities account for $93 \%$ of the volume of industrial wastewaters discharged within the Parisian sewerage systems. At a yearly scale, the total volume generated by industrial activities was estimated at 14 million $\mathrm{m}^{3}$ (Figure 1) (data provided by SIAAP). In addition, these industrial discharges are, thereafter mixed with purely domestic wastewater, and treated by Parisian WWTPs run by SIAAP. In spite of a heavily urbanized but weakly industrialized catchment such as the Parisian one (less than $2 \%$ of wastewater originate from industries for a 8.5 million inhabitants catchment), the contribution of industrial discharges to the global contamination remains unknown and could therefore be used as model to illustrate the evolution of large agglomerations present in industrialized countries. Depending on the industrial activity, the volumes of different sectors strongly vary. Besides, pharmaceutical industries alone account for approximately $40 \%$ of the released volumes (Figure 1a), while vehicle cleaning contributes to less than 3\%. A total of 101 samples were collected on 33 industrial sites connected to the sewerage system. Samples were taken during the working hours; i.e. between $6 \mathrm{~h}(\mathrm{am})$ and $5 \mathrm{~h}(\mathrm{pm}) .75 \%$ of the samples were grab samples while, when it was possible, 24-h average samples have been sampled (25\% of samples). Figure 1 also shows the distribution of samples (b) and facilities (c) according to industrial sectors. Except for the cosmetic industries and the cleaning vehicle sites (i.e. preparation sites for new cars), several sites have been studied for each industrial sector and more than 5 samples were systematically collected. Particular attention was paid to pharmaceutical industries, textile treatment and universities, since their discharged volumes are significant.

For domestic wastewater, a total of 45 samples from 14 different sites were collected within the sewer network. In the Paris conurbation, the ground floor of building often is occupied by small-businesses, whose effluents are mixed with domestic wastewater produced by people living in the upper floors. So it is quite difficult to sample "pure" domestic wastewater. We paid attention to that particular point by selecting dwellings without small-business. Furthermore, samples were collected within a separated sewer network in order to avoid any runoff inputs. Additionally, raw wastewaters transiting within 
Parisian sewer network were also sampled from the main pipes of the Parisian conurbation WWTPs. At a yearly scale, the total volume transiting within SIAAP WWTPs was estimated at 850 million $\mathrm{m}^{3}$ (data provided by SIAAP). Our sampling strategy allows the estimation of the total mass load for industrial effluents. To avoid any contamination and/or pollutant adsorption during sampling, glass bottles and Teflon ${ }^{\circledR}$ pipes were used. Furthermore, blanks of sampling materials were assessed and subtracted in order to avoid contamination issues related to DEHP. Additionally, sampling blanks were statistically repeatable.

\subsection{Routine wastewater quality parameters analysis}

For each sample, routine wastewater quality parameters, such as total suspended solids (TSS), chemical and biochemical oxygen demands $\left(\mathrm{COD}\right.$ and $\left.\mathrm{BOD}_{5}\right)$ and total Kjeldahl nitrogen $(\mathrm{TKN})$ were analyzed. These analyses were performed by LCPP and SIAAP using French standards (COD: NF T90-101; BOD 5 : NF T90-103; TSS: NF EN 872; TKN: NF EN 25663), both are accredited laboratories.

\subsection{Phthalate and alkylphenol analysis}

For each sample, analyses were carried out on both the dissolved and particulate fractions within 24-48 hours after sampling for the dissolved phase, to avoid microbial degradation, and after lyophilization for the particulate phase. Samples were homogenized and then filtered at $0.7 \mu \mathrm{m}$, on glass fiber filters, to separate dissolved and particulate phases. Thus, for the dissolved phase, a volume of $100 \mathrm{ml}$ to $250 \mathrm{ml}$ of sample was extracted by solid phase extraction (SPE). The extraction of contaminants was carried out on C18 cartridge (Supelclean). The cartridge was conditioned by ethyl acetate $(6 \mathrm{ml})$ and methanol ( $2 \times 6 \mathrm{ml}$ ). The sample was then loaded onto the cartridge at $5 \mathrm{ml} / \mathrm{min}$ rates. After rinsing with a volume of $2 \mathrm{ml}$ of a mixture of water/methanol $(95 / 5 ; \mathrm{v} / \mathrm{v})$ and drying under a stream of nitrogen, the cartridge was eluted with $2 \mathrm{ml}$ of ethyl acetate containing two internal standards (perdeuterated DnBP D4 RING and 4-n-NP, linear nonylphenol). For the particulate phase, about $50 \mathrm{mg}$ dry weight of TSS was extracted by $15 \mathrm{~min}$-sonication with $20 \mathrm{ml}$ of ethyl acetate. A second extraction was carried out to ensure complete extraction of the compounds. The dissolved and particulate extracts were then purified on an alumina column (1 g), previously conditioned with $6 \mathrm{ml}$ of ethyl acetate. Thereafter the extracts were concentrated under a stream of nitrogen to a final volume of $1 \mathrm{ml}$ then mixed with $1 \mathrm{ml}$ of ethyl acetate containing the internal standards. Phthalates and alkylphenols were analyzed by gas chromatography 
coupled to a mass spectrometer (single quadruple, Agilent Technologies), equipped with a DB-5MS column (Agilent Technologies, $30 \mathrm{~m}$ ). These molecules were ionized by electronic ionization. The analysis was performed by single ion monitoring (SIM) and our method used one target and two qualifier ions for molecule identification (Table 1). Control solutions (low and midrange points) were injected every ten samples and a drift of less than $20 \%$ of the target value validated results. Because we analyzed separately the two phases, two quantification limits, one for each matrix, were needed. So, for the liquid phase, the quantification limit was $0.20 \mu \mathrm{g} / \mathrm{l}$ for all congeners. This value refers to the method quantification limit and not to the instrument limit detection, i.e., using signal-to-noise ratios. For the solid phase, the quantification limit was $0.05 \mathrm{mg} / \mathrm{kg} \mathrm{dw}$. Extraction blanks were also carried out. When the measured concentrations in blanks were above the liquid phase quantification limit $(0.20 \mu \mathrm{g} / \mathrm{l})$, these values were subtracted from the sample concentrations. Furthermore, sampling blanks were statistically repeatable. Linearity, quantification limits, and analytical uncertainties were assessed using French accreditation procedures (NF $-\mathrm{T}$ 90-210 and $\mathrm{NF}-\mathrm{T}$ 90-220 standards).

\subsection{Fluxes within the sewerage systems}

Annual mass fluxes were calculated for phthalates and alkylphenols within the sewage network supplying the SIAAP WWTPs. These fluxes were calculated from the annual wastewater flows transiting within the Parisian sewage network (i.e. 850 million $\mathrm{m}^{3}$ ) and median concentrations at the annual scale. Fluxes were computed as follows:

$$
\mathrm{F}_{\mathrm{wwtp}}=\mathrm{C}_{\text {pollutant }} \mathrm{X} \mathrm{Q}
$$

Equation 1

Where $\mathrm{F}_{\mathrm{wwtp}}$ is the mass flux in $\mathrm{kg} / \mathrm{yr}, \mathrm{C}_{\text {pollutant }}$ the concentration of the pollutant in $\mathrm{kg} / \mathrm{m}^{3}$ and $\mathrm{Q}$ the annually water flow in $\mathrm{m}^{3} / \mathrm{yr}$

\subsection{Industrial fluxes}

\subsubsection{Industrial fluxes estimation}

To establish a mass balance of industrial discharge fluxes within the sewer network of Paris and its conurbation, phthalates and alkylphenols fluxes were calculated according to the median concentrations as follows:

$$
\mathrm{F}_{\text {Sector }}=\mathrm{C}_{\text {pollutant }} \times \mathrm{Q}
$$


Where, for a given pollutant, $\mathrm{F}_{\text {Sector }}$ is the flux of the sector of activity in $\mathrm{kg} / \mathrm{yr}, \mathrm{C}_{\text {pollutant }}$ the median concentration of the sector of activity in $\mathrm{kg} / \mathrm{m}^{3}$ and $\mathrm{Q}$ the annual water flow of the sector of activity in $\mathrm{m}^{3} / \mathrm{yr}$.

Finally, the sum of each sector flux was used to compute the total industrial flux (in $\mathrm{kg} / \mathrm{yr}$ ):

$$
\mathrm{F}^{\text {industrial }}=\sum \mathrm{F}_{\text {Sector }}
$$

Equation 3

\subsubsection{Extrapolation of fluxes to the Paris conurbation catchment}

Some adjustments between industrial fluxes and those transiting within the sewage of the Parisian agglomeration WWTPs were required to extrapolate the contribution from industrial discharges to the entire Paris conurbation catchment. A corrective factor was applied to industrial fluxes ( $\left.\mathrm{F}^{\text {industrial }}\right)$ in order to take into account the proportion of the total volumes of industrial wastewater (Equation 3). As previously noted, about $93 \%$ of manufacturers connected to the Paris conurbation sewerage systems were considered.

$$
\mathrm{F}_{\text {adjusted }}^{\text {industrial }}=\mathrm{F}^{\text {industrial }} \mathrm{x}(1 / 0.93)
$$

Equation 3

Finally, for a given pollutant, the contribution of the industrial discharges to the pollution transported within the sewerage systems was computed as follows:

$$
\text { Contribution }(\%)=100 \times \mathrm{F}^{\text {industrial }}{ }_{\text {adjusted }} / \mathrm{F}_{\mathrm{wwtp}}
$$

Equation 4

\section{RESULTS AND DISCUSSION}

\subsection{Characterization of industrial inputs to the Paris conurbation sewer}

\subsubsection{Case of Routine wastewater quality parameters}

Routine wastewater quality parameters for the collected discharges are given in Table 1. These parameters and more especially nitrogen provide information on the quality and nature of effluents. Thus, high nitrogen concentrations in some industrial effluents indicate the presence of domestic inputs (toilet waters) inside the industrial discharges. Indeed, high TKN concentration highlights the presence of domestic effluents within the industrial discharges, since TKN is recognized to be a tracer of human activities. Depending on the industrial activity, the routine wastewater quality parameters of different sectors strongly vary. For instance, COD and TSS values are lying in the 15-11,000 $\mathrm{mg} \mathrm{O}_{2} / 1$ and 2-6,000 mg/l ranges, respectively. Hence, several industrial sectors exhibited COD concentrations higher than 
authorized values $\left(>2,000 \mathrm{mg} \mathrm{O}_{2} / \mathrm{l}\right)$; i.e., textile treatment, pharmaceutical industries, transportation maintenance or universities occasionally displayed COD concentrations up to 2,700, 11,000, 2,400 and $2,200 \mathrm{mg} \mathrm{O}_{2} / 1$, respectively.

A comparison between industrial sectors and domestic wastewater concentrations allows differentiating three groups of activities (Figure 2). These groups were compared to raw wastewaters collected from the main trunks of Parisian WWTPs and from purely domestic samples (DOM) as given Table 1. Some sectors present both high COD and TKN concentrations. Thus, the cluster A, included aerospatial industries as well as transportation maintenance and universities: it exhibited COD and TKN

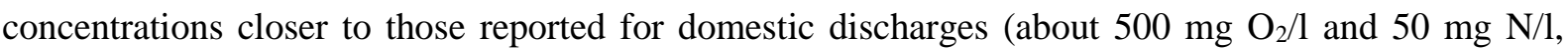
respectively). Additionally, universities and residential discharges indicated the highest TKN concentrations and showed similar COD concentrations (see Table 1 and Figure 2). The cluster B concerned textile treatment and pharmaceutical industries; it displayed the highest COD medians concentrations (above $550 \mathrm{mg} \mathrm{O} / \mathrm{l}$ ) coupled to low TKN concentrations (less than $20 \mathrm{mg} \mathrm{N} / \mathrm{l}$ ). For instance, COD medians concentrations of 1,310 and $553 \mathrm{mg} \mathrm{O}_{2} / \mathrm{l}$ were measured for textile treatment and pharmaceutical industries, respectively. Finally, the cluster $\mathrm{C}$ consisting of industrial sectors exhibited routine wastewater quality parameters concentrations lower than those for domestic discharges. This group included metallurgy, drinking water production, cosmetic industries as well as vehicle cleaning and garbage disposal. These low concentrations were explained by the fact that most of these industrial sites are equipped with their own effluent treatment units that allow reducing the discharge of contaminants in the sewerage systems (effluent neutralization, clarification, biological treatment, etc.).

\subsubsection{Case of phthalates and alkylphenols}

As previously mentioned, for each determinant we assessed its concentrations in both the dissolved (D, expressed as $\mu \mathrm{g} / \mathrm{l})$ and the particulate phases. Hence, the total concentration refers to the sum of dissolved (D) and particulate (P) concentrations, namely (D + P). It was then calculated, by considering SPM concentration, as follows:

$(\mathrm{D}+\mathrm{P})(\mu \mathrm{g} / \mathrm{l})=\mathrm{D}(\mu \mathrm{g} / \mathrm{l})+\mathrm{P}(\mu \mathrm{g} / \mathrm{l})$ with $\mathrm{P}(\mu \mathrm{g} / \mathrm{l})=\mathrm{P}^{*}(\mathrm{mg} / \mathrm{kg} \mathrm{dw}) \times \mathrm{SPM}(\mathrm{mg} / \mathrm{l})$. 
Whatever the nature of effluents, of the 6 molecules targeted, 4 (namely DEP, DEHP, NP and DnBP) were quantified in more than $95 \%$ of the collected samples. BBP was quantified in approximately $80 \%$ while OP was detected in only one-third of industrial effluents. In addition, among the industrial effluents in which OP was quantified, a large majority of the concentrations was close to the limit of quantification; i.e. $0.20 \mu \mathrm{g} / \mathrm{l}$. Results lower than $0.20 \mu \mathrm{g} / \mathrm{l}$ correspond to substances only quantified in the particulate phase (quantification limit of $0.05 \mathrm{mg} / \mathrm{kg} \mathrm{dw}$ ). Overall, a high variability of phthalate and alkylphenol levels was observed. The array of industrial sectors reported and the corresponding concentration ranges were typically representative of data found in literature for industrial wastewaters (Clark et al. 2003, Jackson and Sutton 2008, Sanchez-Avila et al. 2009, Terzic et al. 2008, Vethaak et al. 2005). Concentrations were classified by level ranges in Figure 3; neither temporal variations nor activity sector were considered. Overall, the greatest part of concentrations ranged from the quantification limit to $100 \mu \mathrm{g} / \mathrm{l}$, except for DEHP, where 25 samples $(25 \%)$ presented concentration levels lying between 100 and 1,000 $\mu \mathrm{g} / \mathrm{l}$. Moreover, only DEHP presented concentrations superior to $1,000 \mu \mathrm{g} / \mathrm{l}$, probably as a result of its comparatively higher consumptions when compared to other congeners (Peijnenburg and Struijs 2006). Phthalates and alkylphenols were frequently detected in wastewater from these industrial sectors; most sites are however equipped with sewage treatment plants, reducing the dissemination of these contaminants in sewerage systems. Additionally, some substances were never detected in some industrial activities. For instance, OP was never detected within vehicle cleaning, metallurgy as well as drinking water production sites.

Based on the levels of contamination of alkylphenols and phthalates, three groups of industrial sectors were identified (see Table 2). The first group included industrial sectors exhibiting several contaminants with concentrations above $10 \mu \mathrm{g} / \mathrm{l}$. Textile treatment, universities, transportation maintenance and cosmetics industries were concerned; they displayed the highest median concentrations (10-130 $\mu \mathrm{g} / \mathrm{l})$ for DEP and DEHP, and to a lesser extent NP (up to $55 \mu \mathrm{g} / \mathrm{l}$ ). The presence of these substances results from their extensive use in industry and household applications. DEP and DEHP are currently used as chemical additives in a wide variety of consumer products, such as textile manufacturer, plastics for automotive industry and/or personal care-products (Jackson and Sutton 2008, Lassen et al. 2009). 
Similarly, NP is widely used as an additive in cosmetics (Ying et al. 2002). The second group contained sectors for which pollution was mainly due to only one contaminant. This group consisted of aerospace and pharmaceutical industries; with DEHP median concentration of about $12 \mu \mathrm{g} / \mathrm{l}$. Meanwhile, the other compounds were observed in effluents at median concentrations lying between 0.50 and $3.00 \mu \mathrm{g} / 1$; i.e., 4 to 25 fold lower than DEHP. Besides, pharmaceutical industries presented the highest concentration of OP lying between 0.02 and $13.9 \mu \mathrm{g} / \mathrm{l}$ (median, $1.00 \mu \mathrm{g} / \mathrm{l}$ ). This was explained by the extended use of OP in pharmaceutical products formulation. The last group included sectors for which concentration levels for all contaminants were below $10 \mu \mathrm{g} / \mathrm{l}$. This group contained vehicle cleaning, garbage disposal, surface treatment, metallurgy, and drinking water production.

The variability of the sums of total phthalates (PAEs) and alkylphenols (APs) among sectorial activities can be examined in more details using Figure 4 in order to determine their statistical distribution. This figure presents data from eleven industrial sector, domestic and WWTP datasets; this figure provides the $10^{\text {th }}$ and $90^{\text {th }}$ percentiles (namely "the whiskers"), and the $25^{\text {th }}$ and $75^{\text {th }}$ percentiles ("the boxes") along with the median concentrations. This figure also shows the variability of concentrations (i) within an industrial sector and (ii) between all studied sectors. As illustrated by Figure 4, textile treatment and cosmetics industries as well as transportation maintenance and universities exhibited the highest concentrations both for phthalates and alkylphenols. Similar levels were obtained, for a similar watershed, in the framework on the French research program based on the Research and the Reduction of Releases of Hazardous Substances in the Environment (INERIS 2007).

Since it has been established that physicochemical properties are responsible of the fate and the behavior of pollutant in both liquid and solid matrices, especially in urban areas, data concerning the distribution of phthalates and alkylphenols was assessed in both industrial and domestic effluents. According to our database, different profiles can be distinguished in contaminant distributions between dissolved and particulate fractions. For instance, DEP, DnBP, NP and OP (log $\mathrm{K}_{\text {ow }}$ equal to 2.4, 4.6, 4.5 and 4.1, respectively) were mainly quantified in the dissolved fraction $(93 \%, 80 \%, 88 \%$ and $81 \%)$. BBP $\left(\log \mathrm{K}_{\text {ow }}\right.$ of 4.8) was equally distributed between the two phases (55-45\%, respectively). Finally, DEHP ( $\log \mathrm{K}_{\text {ow }}$ of 7.5) was preferentially associated to particles (82\%), as most of hydrophobic pollutants. Moreover, 
the distributions measured between the two phases were statistically different regardless of those obtained in the effluent collected at the outfall of sewerage systems. Therefore, the proportion on the particulate phase was higher for some compounds, including NP (50-50\% between the two phases), OP (48-52\% for dissolved and particulate phases, respectively) and to a lesser extent DnPB (58-42\%). This confirmed the existence of sorption processes occurring all along the wastewater sewer. As regards contaminant contents, no groups of industrial sectors were distinguished (see Table 2). Overall, DEHP presented the highest contents, whatever the industrial sector concerned; it displayed median contents lying between 30 and 3,000 mg/kg dry weight. Data recorded for alkylphenols and phthalates in industrial particles do not exist so far. For the eleven investigated industrial sectors, the median levels of nonylphenol lay in the range of $5-50 \mathrm{mg} / \mathrm{kg}$ dry weight. Besides, for all investigated compounds, the vehicle cleaning sector underscored median content levels in the higher range whereas its concentrations were in the lowest range (Table 2). An opposite trend was observed for textile treatment, universities and transportation maintenance, for which median content levels were in the lower range while concentrations were in the higher one. This underlined the presence of particles of various natures in the different industrial effluents. In most sectors (cosmetic industries and/or transportation maintenance for instance - Table 2), DEP presented higher content levels than DnBP and BBP, recognized as to be heavier phthalates and therefore preferentially bound to particles.

\subsection{Characterization of sewer domestic inputs}

\subsubsection{Case of routine wastewater quality parameters}

Routine wastewater quality parameters were analyzed in domestic wastewater (see Table 2). It is important to note that wastewater was sampled upstream of the sewer network just after their release. Table 2 provides information on domestic wastewater quality. Although a large range of concentrations was observed, it was possible to characterize domestic wastewater with respect to two key parameters,

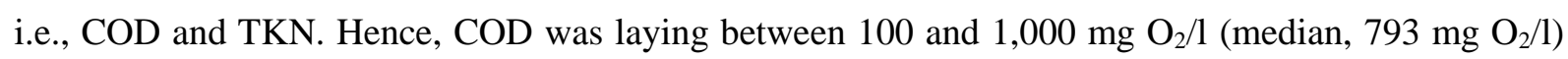
and TKN ranged from 5 to $260 \mathrm{mg} \mathrm{N} / 1$ (median, $95 \mathrm{mg} \mathrm{N} / \mathrm{l}$ ). These results were higher than those reported by Bergé (2012b), by a quite steady factor of 1.7, when compared to effluents of two SIAAP WWTPs (namely Seine-Centre and Seine-Aval), located downstream of the sewer network. Those effluents displayed median concentrations of about $480 \mathrm{mg} \mathrm{O}_{2} / \mathrm{l}$ for COD and $55 \mathrm{mg} \mathrm{N} / \mathrm{l}$ for TKN, 
respectively. This latter finding suggests that i) dilution of domestic effluents by parasitic water (such as infiltration of groundwater into sewer pipe, street cleaning water, etc.) and ii) in-sewer processes, such as biodegradation pathways, acted within the sewerage systems and transformed and/or degraded the organic matter. Compared to industrial discharges, the quality of domestic wastewater was very close to that observed for universities. Therefore university effluents were assimilated as domestic wastewater. These effluents mainly derived from black water rather than from research laboratories and/or practical training rooms.

\subsubsection{Case of phthalates and alkylphenols}

For domestic wastewater, five substances were systematically quantified; OP was only detected in about $70 \%$ of samples. As reported in Table 2, DEHP represented the predominant phthalate (accounting for $75 \%$ of all phthalates). Domestic concentrations of DEHP in this study were within the 7-460 $\mu \mathrm{g} / \mathrm{l}$ range (median, $40.7 \mu \mathrm{g} / \mathrm{l}$ ), that is to say the upper range of the literature (Jackson and Sutton 2008, SanchezAvila et al. 2009, Vethaak et al. 2005). DEP was also present in most samples and exhibited significant concentration levels; domestic DEP levels were in the 1.82-140 $\mu \mathrm{g} / \mathrm{l}$ range (median, $10.1 \mu \mathrm{g} / \mathrm{l}$ ). These results were in good agreement with those reported by Vethaak et al. (2005) and Jackson and Sutton (2008) for Dutch (4.10-44.0 $\mu \mathrm{g} / \mathrm{l})$ and American (4.00-9.10 $\mu \mathrm{g} / \mathrm{l})$ domestic effluents, respectively, but were significantly lower to those reported by Sanchez-Avila et al. (2009) for Spanish residential effluents $(44.0-45.9 \mu \mathrm{g} / \mathrm{l})$. The presence of DEP in domestic wastewater was explained by its uses in household products. Indeed, DEP is typically employed as component of fragrance in personal care products, housekeeping products and other consumer items (Jackson and Sutton 2008). Alkylphenol concentrations lay between 1 and $40 \mu \mathrm{g} / \mathrm{l}$ (median, $9.04 \mu \mathrm{g} / \mathrm{l}$ ) for NP and up to $4 \mu \mathrm{g} / \mathrm{l}$ (median, $0.89 \mu \mathrm{g} / \mathrm{l}$ ) for OP. These concentration ranges were comparable to values reported in the literature for domestic wastewater (Bergé et al. 2012a, Jackson and Sutton 2008, Sanchez-Avila et al. 2009, Terzic et al. 2008, Vethaak et al. 2005). The analysis of contaminant contents highlights the preponderance of DEHP in the particles from domestic effluents (Table 2). Based on the 45 samples investigated, the levels of nonylphenol in domestic wastewater was in the range of $5.32-154 \mathrm{mg} / \mathrm{kg}$ dry weight (median, 13.9 $\mathrm{mg} / \mathrm{kg} \mathrm{dw}$. DEP, DnBP and BBP were ubiquitous regardless of their occurrence and levels. For example, DnBP was measured in the 1.14-44.2 mg/kg dry weight range (median, $4.56 \mathrm{mg} / \mathrm{kg} \mathrm{dw}$ ). When 
compared to industrial discharges, the levels reported for domestic wastewater were in the lower range of industrial contents. Moreover, the contents in domestic effluents were close to those reported for universities, confirming that university effluents could be considered as domestic wastewater as previously mentioned for routine wastewater quality parameters.

\subsection{Fluxes within the sewerage systems}

Table 3 summarizes the total mass fluxes of phthalates and alkylphenols, within the sewage of Parisian WWTPs. At the whole catchment scale, the variations of phthalates and alkylphenols appear to be not relevant, with coefficients of variation lying between 20 and $40 \%$ (Table 3 ) for all compounds. This variability reinforces the idea that, in a large watershed such as Paris and its conurbation, to reason at the whole watershed scale seems to be smarter than to analyze separately each WWTP sub-watershed. Generally speaking, DEHP present the abundant contaminant flux with a median flux of $45,685 \mathrm{~kg} / \mathrm{yr}$ ( $85 \%$ of the total phthalate flux), followed by DEP $(6,869 \mathrm{~kg} / \mathrm{yr}-13 \%)$.

\subsection{Inter-comparison of industrial fluxes by industrial activity}

Table 7 summarizes the mass fluxes of COD, TKN, phthalates and alkylphenols in industrial discharges. The textile treatment industry, namely industrial laundries, represented the main contribution of DEHP and DEP contamination for industrial effluents; it displayed the highest median fluxes with levels of 235 and $69 \mathrm{~kg} / \mathrm{yr}$, respectively. The flux of DnBP predominantly originated from the pharmaceutical industry $(9 \mathrm{~kg} / \mathrm{yr})$. A significant flux of BBP was measured within the effluents from the facilities of drinking water production $(12 \mathrm{~kg} / \mathrm{yr})$. This flux mainly contributed to the total industrial flux of BBP (55\%). No explanation has however been brought to explain the sectorial contribution for this congener. Pharmaceutical industries, universities and textile treatment were the main vectors of NP in industrial discharges with respective levels of 18,17 and $15 \mathrm{~kg} / \mathrm{yr}$. Finally, and out the sectors studied, the OP seemed mostly provided by the pharmaceutical industries $(5 \mathrm{~kg} / \mathrm{yr}$, or $64 \%)$. Overall, DEHP showed the largest flux with $407 \mathrm{~kg} / \mathrm{yr}$, followed by DEP (162 kg/yr) and NP (72 kg/yr). DnBP and BBP fluxes were similar: 23 and $22 \mathrm{~kg} / \mathrm{yr}$, respectively. Finally, OP showed the lowest industrial flux (below 10 $\mathrm{kg} / \mathrm{yr}$ ). As can be seen from Table 7, for some congeners, the highest fluxes did not originate from sectors that generate the highest wastewater volumes. For instance, $19 \mathrm{~kg} / \mathrm{yr}$ (about $12 \%$ of the total flux) was provided by the cosmetic industry for DEP while this sector only accounts for about $1 \%$ of 
the total volume of industrial wastewater. A similar trend was observed for NP. For DnBP and OP, a significant correlation between the wastewater volume and the flux generated by an activity has been underlined. Indeed, by significantly contributing to industrial wastewater flow (39\%, Table 7), the pharmaceutical industries provided a considerable proportion of DnBP and OP (39 and 64\%, respectively).

Figure 5 illustrates the contributions of the various industrial sectors for each substance. Based on these contributions of the different industrial sectors to the flux of contamination for all the molecules, the industrial sectors were divided in four groups. Thus, the first group, including textile treatment and pharmaceutical industries, showed a significant contribution of these activities for almost all the molecules (i.e., superior to $15 \%$ ). For instance, the textile treatment contribution ranged between $16 \%$ for BBP and 58\% for DEHP, with intermediate values for NP (21\%), DnBP (38\%) and DEP (43\%). The second group comprises universities, for which a quite homogeneous distribution was observed for all molecules (between 5 and 25\%). The third group includes an industrial sector for which only one molecule mainly contributed to the contamination, namely the drinking water production sites (with DnBP around 55\%). Finally, the last group contains the remaining industrial sectors, for which, whatever the molecule considered, the industrial contribution was below $15 \%$; i.e. aerospace industries, metallurgy, garbage disposal, transportation maintenance, cosmetic industries, vehicle cleaning and surface treatment sites (Figure 5). Interestingly, NP sectorial distribution differed from that of any other substance. Indeed, no sector appeared significantly more contributing than any other. This difference might be due to the large spectrum of uses of NP in urban areas.

\subsection{Contribution of industrial discharges to pollution within the sewerage systems}

As regard fluxes (Table 7), the contribution of industrial discharges was relatively low compared to the pollution within the Parisian sewerage system. As previously noted in Table 7, DEP and DnBP exhibited the highest industrial contribution, with levels up to $2.5 \%$ of the total flux. In contrast, OP industrial discharge only account for $0.7 \%$. DEHP, NP and BBP presented intermediate values: 1.0, 1.3 and 2.0\%, respectively. Similar trends were computed for routine wastewater quality parameter with industrial contribution do not exceeding 2.5\%. For instance, COD and TKN exhibited industrial contribution of 2.3 and $0.8 \%$, respectively. This insignificant contribution of industry could be explained by considering 
the characteristics of the Paris conurbation watershed. Indeed, this watershed is considered as a highly urbanized but is weakly industrialized. This low industrialization is noticeable by the minor contribution of industrial wastewater (1.6\% of the total water flow). It can be seen from the data in Table 7 that the industrial contribution for some substances (especially for DEHP, NP and OP for hazardous substances and TKN for routine wastewater quality parameter) was lower than the contribution of the total industrial water flow. Besides, our results reinforced that TKN can be recognized to be a tracer of human activities. Additionally, it is reasonable to assume that the numerous recent efforts granted by industry to treat its effluents have contributed to reduce their pollutant discharges.

\section{CONCLUSIONS}

This study provides an overview of industrial fluxes at the scale of the watershed of the Paris conurbation by assessing the contribution of some phthalates and alkylphenols by industrial discharges to the total fluxes entering the main WWTPs. Thus, for a highly urbanized but weakly industrialized watershed such as Paris conurbation, the contribution of industrial discharges to the total flux is minor. This work has confirmed, first and foremost, that phthalates and alkylphenols are indeed highly concentrated in industrial wastewater. As expected, DEHP was present in all samples at significant concentrations, reflecting its ubiquitous nature. The analysis of industrial discharges by sector of activity highlighted that some substances were quantified in most of the studied sectors, especially DEHP, DEP and NP. In contrast, other compounds, including BBP, were only detected in the discharges of some activities. Finally, OP was little quantified. Of the practitioner point of view, no correlation was found between routine wastewater quality parameters and the micro-pollutants. Furthermore, no trend has been distinguished on a seasonal variability of phthalates, and alkylphenols, both within domestic and industrial sites.

This work showed that phthalates and alkylphenols were also detected in purely domestic wastewater, i.e., without industrial effluent. They were observed at higher concentrations than expected. Indeed, the analysis of residential discharges underscored that these substances were quantified at the same levels than those for industrial discharges, confirming the ubiquitous nature of these substances in urban environment. Furthermore, this work pointed out that phthalate and alkylphenol disseminations were related to both domestic and industrial activities. This study also highlighted that levels (both 
concentrations and contents) reported for some industrial sectors were close to those measured in domestic discharges.

The inter-comparison of industrial sectors confirmed the ubiquity of phthalates and alkylphenols in urban areas, preferentially in industrial discharges. Moreover, this work has emphasized some disparities, especially between industrial and domestic discharges. This information has allowed identifying principal contributors for each substance. If textile treatment industries mainly disseminated DEP and DEHP (43 and 58\%, respectively), pharmaceutical industries contributed extensively to the release of DnBP (39\%), NP (26\%) and OP (64\%). As previously mentioned, some industrial sectors, such as textile treatment and universities which significantly contribute to industrial discharges, could be assimilated to household activities. This could minimize most considerably industrial contributions. However, further investigations for most congeners are needed in both domestic and industrial discharges to complete source characterization and to elucidate domestic contribution. By providing significant knowledge on the quality of industrial and domestic wastewater, this study might be used in the future to identify hazardous substances sources.

The data generated during this work could also be used in the future to identify their dissemination sources in urban areas. this study constitutes one of the first relevant approach to provide accurate knowledge on the occurrence and the contribution of these substances in urban environment and their significance with respect to industrial and domestic wastewaters.

\section{ACKNOWLEDGEMENTS}

The authors gratefully acknowledge Nacer Ouldamara (SEVESC) as well as Céline Briand and Sabrina Guérin (SIAAP) for their technical assistance during the sampling campaigns. The authors also thank Nolwenn Helliot (Environmental Health Management - SIAAP) for her participation to this work.

\section{REFERENCES}

Bergé A, Cladière M, Gasperi J, Coursimault A, Tassin B, Moilleron R (2013): Meta-analysis of environmental contamination by phthalates. Environmental Science and Pollution Research, 20 (11), $8057-8076$ 
Bergé A, Cladière M, Gasperi J, Coursimault A, Tassin B, Moilleron R (2012a): Meta-analysis of environmental contamination by alkylphenols. Environmental Science and Pollution Research 19(9), 3798-3819

Bergé A (2012b): Identification of sources of alkylphenols and phthalates in urban area. Comparison of domestic discharges to pure industrial wastewater (thesis), University Paris-Est, Créteil, 290 pp

Clark K, Cousins I, MacKay D (2003): Assessment of critical exposure pathways. In: Staples CA (Editor), The Handbook of Environmental Chemistry. Springer, New York

EU (2000): 2000/60/EC of the European Parliament and of the Council establishing a Framework for Community action in the field of water policy. Official Journal of the European Union, Luxembourg

EU (2001) Decision No. 2455/2001/EC of the European Parliament and of the Council establishing the list of priority substances in the field of water policy and amending Directive 2000/60/EC.

EU (2008): Directive 2008/105/EC of the European Parliament and of the Council of 16 December 2008 on environmental quality standards in the field of water policy, amending and subsequently repealing Council directives 82/176/EEC, 83/513/EEC, 84/156/EEC, 84/491/EEC, 86/280/EEC and amending Directive 2000/60/EC

Fountoulakis MS, Stamatelatou K, Bastone DJ, Lyberatos G (2006): Simulation of DEHP biodegradation and sorption during the anaerobic digestion of secondary sludge. Water Science and Technology 54, 119-128

Giger W, Gabriel FdrLP, Jonkers N, Wettstein FE, Kohler H-PE (2009): Environmental fate of phenolic endocrine disruptors: field and laboratory studies. Philosophical Transactions of the Royal Society A: Mathematical, Physical and Engineering Sciences 367, 3941-3963

Harrison EZ, Oakes SR, Hysell M, Hay A (2006): Organic chemicals in sewage sludges. Science of The Total Environment 367, 481-497

INERIS (2007): Regional action of search and reduction discharges of dangerous substances in water by the classified installations and the urban wastewater treatment plants (in French), INERIS, Verneuilen-Halatte, Oise, France 
Jackson J, Sutton R (2008): Sources of endocrine-disrupting chemicals in urban wastewater, Oakland, CA. Science of the Total Environment 405, 153-160

John DM, White GF (1998): Mechanism for Biotransformation of Nonylphenol polyethoxylates to xenoestrogens in Pseudomonas putida. Journal of Bacteriology 180, 4332-4338

Lassen C, Maag J, Hubschmann JB, Hansen E, Searl A, Doust E, Corden C (2009): Data on manefacture, import, export, uses and releases of Bis(2-ethylhexyl)phthalate (DEHP) as well as information on potential alternatives to its use. COWI, IOM and Entec report to ECHA

Lund T (2000): Note on endocrine disrupting compounds. Commission of the Public Health and Consumer Policy. European Parliament, 1999 - 2004

Peijnenburg WJGM, Struijs J (2006): Occurrence of phthalate esters in the environment of the Netherlands. Ecotoxicology and Environmental Safety 63, 204-215

Pryor SW, Hay AG, Walker LP (2002): Nonylphenol in anaerobically digested sewage sludge from New York state. Environmental Science and Technology 36, 3678-3682

Purdom CE, Hardiman PA, Bye VJ, Eno NC, Tyler CR, Sumpter JP (1994): Estrogenic effects of effluents from sewage treatment works. Chemical Ecology 8, 275-285

Sanchez-Avila J, Bonet J, Velasco G, Lacorte S (2009): Determination and occurrence of phthalates, alkylphenols, bisphenol A, PBDEs, PCBs and PAHs in an industrial sewage grid discharging to a Municipal Wastewater Treatment Plant. Science of The Total Environment 407, 4157-4167

Terzic S, Senta I, Ahel M, Gros M, Petrovic M, Barcelo D, Müller J, Knepper T, Marti I, Ventura F, Jovancic P, Jabucar D (2008): Occurrence and fate of emerging wastewater contaminants in Western Balkan Region. Science of The Total Environment 399, 66-77

Vethaak AD, Lahr J, Schrap SM, Belfroid AlC, Rijs GBJ, Gerritsen A, de Boer J, Bulder AS, Grinwis GCM, Kuiper RV, Legler J, Murk TAJ, Peijnenburg W, Verhaar HJM, de Voogt P (2005): An integrated assessment of estrogenic contamination and biological effects in the aquatic environment of The Netherlands. Chemosphere 59, 511-524 
Xie Z, Ebinghaus R, Temme C, Lohmann R, Caba A, Ruck W (2007): Occurrence ans Air-Sea exchange of phthalates in the Arctic. Environmental Science and Technology 41, 4555-4560

Ying G-G, Williams B, Kookana R (2002): Environmental fate of alkylphenols and alkylphenol ethoxylates: a review. Environment International 28, 215-226 
Table 1: Qualifier and quantifier transitions used for the analysis of alkylphenols and phthalates

\begin{tabular}{|l|l|l|c|}
\hline & M $(\mathrm{g} / \mathrm{mol})$ & Quantifier ion $(\mathrm{m} / \mathrm{z})$ & Qualifier ion $(\mathrm{m} / \mathrm{z})$ \\
\hline DEP & 222,2 & 149 & $177(24 \%)-222(3 \%)$ \\
\hline DnBP & 278,4 & 149 & $205(5 \%)-223(5 \%)$ \\
\hline BBP & 312,4 & 149 & $206(25 \%)-238(5 \%)$ \\
\hline DEHP & 390,6 & 149 & $167(30 \%)-279(10 \%)$ \\
\hline NP & 220 & 135 & $107-220$ \\
\hline OP & 206 & 135 & $107-206$ \\
\hline
\end{tabular}

The percentages in brackets are the ratios of the qualifier ion over the quantifier ion 
Table 2: Routine wastewater quality parameters for industrial, domestic and WWTP wastewaters

\begin{tabular}{|c|c|c|c|c|c|c|}
\hline \multirow{2}{*}{ Sector of activity } & \multirow{2}{*}{$\mathrm{n}$} & \multirow{2}{*}{$\mathrm{m}$} & COD & $\mathrm{BOD}_{5}$ & TSS & TKN \\
\hline & & & $\mathrm{mg} \mathrm{O}_{2} / \mathrm{l}$ & $\mathrm{mg} \mathrm{O}_{2} / 1$ & $\mathrm{mg} / \mathrm{l}$ & $\mathrm{mg} \mathrm{N} / \mathrm{l}$ \\
\hline Textile treatment $(\mathrm{TT})$ & 18 & 5 & $\begin{array}{c}206-2,746 \\
(1,310)\end{array}$ & $\begin{array}{c}61-1,300 \\
(535)\end{array}$ & $\begin{array}{c}40-370 \\
(139)\end{array}$ & $\begin{array}{c}4.9-28.2 \\
(15.0)\end{array}$ \\
\hline Pharmaceutical industries (PHA) & 17 & 4 & $\begin{array}{c}19-11,040 \\
(553)\end{array}$ & $\begin{array}{c}4-7,360 \\
(190)\end{array}$ & $\begin{array}{c}10-700 \\
(49)\end{array}$ & $\begin{array}{c}0.4-54.5 \\
(6.0)\end{array}$ \\
\hline Aerospace industries (AER) & 7 & 2 & $\begin{array}{c}104-762 \\
(350) \\
\end{array}$ & $\begin{array}{c}42-170 \\
(97) \\
\end{array}$ & $\begin{array}{c}7-68 \\
(9) \\
\end{array}$ & $\begin{array}{c}21.8-86.7 \\
(48.3) \\
\end{array}$ \\
\hline Garbage disposal (GD) & 9 & 2 & $\begin{array}{c}47-1,570 \\
(169)\end{array}$ & $\begin{array}{c}12-860 \\
(59)\end{array}$ & $\begin{array}{c}3-1,420 \\
(33)\end{array}$ & $\begin{array}{c}1.8-118.0 \\
(12.1)\end{array}$ \\
\hline Vehicle cleaning (VC) & 3 & 2 & $\begin{array}{c}27-241 \\
(29) \\
\end{array}$ & $\begin{array}{c}6-71 \\
(8) \\
\end{array}$ & $\begin{array}{r}9-16 \\
(12) \\
\end{array}$ & $\begin{array}{c}0.4-6.0 \\
(2.7)\end{array}$ \\
\hline Cosmetic industries (CI) & 2 & 1 & $\begin{array}{c}66-435 \\
(251)\end{array}$ & $\begin{array}{c}34-140 \\
(87)\end{array}$ & $\begin{array}{l}3-18 \\
(11)\end{array}$ & $\begin{array}{c}0.9-6.0 \\
(3.5)\end{array}$ \\
\hline Surface treatment (ST) & 7 & 4 & $\begin{array}{c}30-489 \\
(253)\end{array}$ & $\begin{array}{c}5-277 \\
(83)\end{array}$ & $\begin{array}{c}4-1,210 \\
(17)\end{array}$ & $\begin{array}{c}0.3-72.7 \\
(29.4)\end{array}$ \\
\hline Metallurgy (M) & 9 & 2 & $\begin{array}{c}17-208 \\
(101)\end{array}$ & $\begin{array}{l}4-71 \\
(25)\end{array}$ & $\begin{array}{l}6-86 \\
(18)\end{array}$ & $\begin{array}{c}0.6-25.2 \\
(6.0)\end{array}$ \\
\hline Transportation maintenance (TM) & 7 & 5 & $\begin{array}{c}54-2,430 \\
(545)\end{array}$ & $\begin{array}{c}12-870 \\
(170)\end{array}$ & $\begin{array}{c}2-384 \\
(97)\end{array}$ & $\begin{array}{c}1.5-144.0 \\
(55.2)\end{array}$ \\
\hline Drinking water production (DWP) & 5 & 2 & $\begin{array}{c}10-862 \\
(17)\end{array}$ & $\begin{array}{c}3-37 \\
(3)\end{array}$ & $\begin{array}{c}2-6,000 \\
(26)\end{array}$ & $\begin{array}{c}1.0-41.9 \\
(2.0)\end{array}$ \\
\hline Universities (UNI) & 17 & 4 & $\begin{array}{c}246-2,203 \\
(531)\end{array}$ & $\begin{array}{c}88-840 \\
(210)\end{array}$ & $\begin{array}{c}72-1,400 \\
(250)\end{array}$ & $\begin{array}{c}35.5-237.0 \\
(105.0)\end{array}$ \\
\hline Domestic (DOM) & 45 & 14 & $\begin{array}{c}96-1,082 \\
(793)\end{array}$ & $\begin{array}{c}20-540 \\
(260)\end{array}$ & $\begin{array}{c}59-2,293 \\
(360)\end{array}$ & $\begin{array}{c}4.8-264.1 \\
(95.0)\end{array}$ \\
\hline WWTP wastewaters (WWTP) & 24 & 4 & $\begin{array}{c}185-584 \\
(428)\end{array}$ & $\begin{array}{c}120-280 \\
(195)\end{array}$ & $\begin{array}{c}169-377 \\
(221)\end{array}$ & $\begin{array}{c}48.0-94.0 \\
(58.5)\end{array}$ \\
\hline
\end{tabular}


Table 3: Concentrations and contents of phthalates and alkyphenols for industrial, domestic and WWTP wastewaters

\begin{tabular}{|c|c|c|c|c|c|c|c|c|c|c|}
\hline \multirow[b]{2}{*}{ Sector of activity } & \multirow[b]{2}{*}{$\mathrm{n}$} & \multirow[b]{2}{*}{$\mathrm{m}$} & \multirow[b]{2}{*}{ Substance } & \multicolumn{4}{|c|}{$\mathrm{D}+\mathrm{P}($ in $\mu \mathrm{g} / \mathrm{l})$} & \multicolumn{3}{|c|}{$\mathrm{P}^{*}$ (in $\mathrm{mg} / \mathrm{kg} \mathrm{dw}$ ) } \\
\hline & & & & $\begin{array}{c}\text { Occurrence } \\
(\%)\end{array}$ & Min & Med & $\operatorname{Max}$ & Min & Med & Max \\
\hline \multirow{6}{*}{ Textile treatment } & \multirow{6}{*}{18} & \multirow{6}{*}{5} & DEP & 100 & 2.87 & 39.8 & 76.3 & 1.09 & 6.47 & 54.0 \\
\hline & & & DnBP & 100 & 2.26 & 4.99 & 14.9 & 1.63 & 10.3 & 36.3 \\
\hline & & & BBP & 100 & 0.44 & 2.09 & 6.08 & 1.34 & 6.23 & 37.0 \\
\hline & & & DEHP & 100 & 38.8 & 135 & 248 & 92.9 & 395 & 1,657 \\
\hline & & & NP & 100 & 2.51 & 8.68 & 21.8 & 3.02 & 7.71 & 94.8 \\
\hline & & & OP & 33 & $0.02^{\mathrm{a}}$ & 0.37 & 1.17 & 0.27 & 0.59 & 0.91 \\
\hline \multirow{6}{*}{$\begin{array}{l}\text { Pharmaceutical } \\
\text { industries }\end{array}$} & \multirow{6}{*}{17} & \multirow{6}{*}{4} & DEP & 100 & 0.47 & 3.36 & 137 & 0.35 & 6.42 & 73.9 \\
\hline & & & DnBP & 100 & 0.48 & 1.66 & 6.96 & 0.62 & 6.23 & 46.7 \\
\hline & & & BBP & 82 & $0.13^{\mathrm{a}}$ & 0.80 & 2.90 & 0.36 & 3.92 & 21.5 \\
\hline & & & DEHP & 100 & 0.60 & 13.3 & 386 & 71.9 & 262 & 3,834 \\
\hline & & & NP & 100 & 0.46 & 3.37 & 42.4 & 1.87 & 8.91 & 287 \\
\hline & & & OP & 29 & $0.02^{\mathrm{a}}$ & 1.00 & 13.9 & 1.50 & 6.47 & 123 \\
\hline \multirow{6}{*}{$\begin{array}{l}\text { Aerospace } \\
\text { industries }\end{array}$} & \multirow{6}{*}{7} & \multirow{6}{*}{2} & DEP & 100 & 0.22 & 0.64 & 4.85 & 2.14 & 12.8 & 18.8 \\
\hline & & & DnBP & 100 & 0.44 & 0.62 & 1.19 & 1.79 & 9.56 & 53.8 \\
\hline & & & BBP & 86 & $0.03^{\mathrm{a}}$ & 0.29 & 2.21 & 1.09 & 19.4 & 30.0 \\
\hline & & & DEHP & 100 & 0.80 & 11.7 & 33.3 & 24.5 & 194 & 1,120 \\
\hline & & & NP & 100 & 1.04 & 2.87 & 5.86 & 3.30 & 9.75 & 195 \\
\hline & & & OP & 14 & $0.03^{\mathrm{a}}$ & $0.03^{\mathrm{a}}$ & $0.03^{\mathrm{a}}$ & 1.11 & 1.11 & 1.11 \\
\hline \multirow{6}{*}{ Garbage disposal } & \multirow{6}{*}{9} & & DEP & 100 & 0.57 & 4.31 & 38.0 & 3.67 & 17.0 & 117 \\
\hline & & & DnBP & 89 & 0.13 & 1.39 & 2.93 & 0.80 & 8.09 & 37.5 \\
\hline & & & BBP & 67 & 0.16 & 0.46 & 1.34 & 0.79 & 4.63 & 11.1 \\
\hline & & 2 & DEHP & 100 & 1.13 & 2.58 & 192 & 8.67 & 43.5 & 4,294 \\
\hline & & & NP & 100 & 0.55 & 2.03 & 18.07 & 0.92 & 4.43 & 407 \\
\hline & & & OP & 33 & 0.21 & 0.53 & 3.33 & 3.80 & 3.80 & 3.80 \\
\hline & & & DEP & 100 & 1.33 & 1.96 & 13.8 & 13.6 & 67.2 & 121 \\
\hline & & & DnBP & 100 & 0.75 & 1.11 & 2.48 & 8.83 & 32.3 & 55.8 \\
\hline & & & BBP & 67 & 0.43 & 0.94 & 1.45 & 6.81 & 36.3 & 65.8 \\
\hline venicle cleaning & 3 & 2 & DEHP & 100 & 5.52 & 6.64 & 21.0 & 368 & 559 & 1,454 \\
\hline & & & NP & 100 & 1.51 & 3.74 & 5.67 & 18.8 & 29.4 & 255 \\
\hline & & & OP & 0 & nd & nd & nd & nd & nd & $\mathrm{Nd}$ \\
\hline & & & DEP & 100 & 112 & 116 & 120 & 50.6 & 113 & 176 \\
\hline & & & DnBP & 100 & 0.37 & 0.78 & 1.19 & 17.2 & 17.3 & 17.4 \\
\hline Cosmetic & 2 & & BBP & 50 & $0.04^{\mathrm{a}}$ & $0.04^{\mathrm{a}}$ & $0.04^{\mathrm{a}}$ & 13.7 & 13.7 & 13.7 \\
\hline industries & 2 & 1 & DEHP & 100 & 6.04 & 45.6 & 85.2 & 1,599 & 3,135 & 4,672 \\
\hline & & & NP & 100 & 51.9 & 54.5 & 57.0 & 48.1 & 54.0 & 59.9 \\
\hline & & & OP & 0 & $0.02^{\mathrm{a}}$ & $0.02^{\mathrm{a}}$ & 0.02 & 1.11 & 1.11 & 1.11 \\
\hline & & & DEP & 100 & 0.43 & 1.67 & 2.50 & 0.41 & 1.36 & 2.75 \\
\hline & & & DnBP & 100 & 0.73 & 0.90 & 2.52 & 0.36 & 3.08 & 5.45 \\
\hline Surface treatment & 7 & 4 & BBP & 57 & 0.23 & 0.26 & 0.52 & 5.45 & 5.45 & 5.45 \\
\hline surrace treatment & 1 & 4 & DEHP & 100 & 0.31 & 1.12 & 1,194 & 6.13 & 26.4 & 13,309 \\
\hline & & & NP & 100 & $0.16^{\mathrm{a}}$ & 2.44 & 3.38 & 0.13 & 6.22 & 22.1 \\
\hline & & & $\mathrm{OP}$ & 57 & 0.28 & 0.52 & 1.58 & 0.53 & 4.58 & 8.64 \\
\hline & & & DEP & 100 & 0.33 & 1.27 & 2.97 & 0.71 & 6.37 & 35.7 \\
\hline & & & DnBP & 100 & $0.11^{\mathrm{a}}$ & 0.44 & 1.28 & 1.05 & 1.84 & 53.2 \\
\hline Metalluroy & 9 & 2 & BBP & 56 & $0.03^{\mathrm{a}}$ & 0.25 & 0.69 & 0.71 & 1.74 & 3.29 \\
\hline Mietanturgy & 9 & 2 & DEHP & 100 & 0.29 & 1.90 & 20.8 & 13.8 & 123 & 406 \\
\hline & & & NP & 100 & 0.53 & 1.93 & 5.61 & 3.67 & 10.7 & 71.7 \\
\hline & & & OP & 0 & nd & nd & nd & nd & nd & $\mathrm{Nd}$ \\
\hline & & & DEP & 100 & 2.66 & 23.4 & 99.5 & 0.90 & 12.6 & 205 \\
\hline Transportation & 7 & 5 & DnBP & 100 & 0.78 & 1.73 & 30.5 & 1.34 & 3.29 & 29.7 \\
\hline maintenance & r & $J$ & BBP & 100 & 0.26 & 0.58 & 31.7 & 1.93 & 6.67 & 36.4 \\
\hline & & & DEHP & 100 & 13.5 & 58.9 & 701 & 45.2 & 667 & 5,666 \\
\hline
\end{tabular}




\begin{tabular}{|c|c|c|c|c|c|c|c|c|c|c|}
\hline & & & $\mathrm{NP}$ & 100 & 4.65 & 11.2 & 281 & 2.59 & 8.70 & 57.0 \\
\hline & & & OP & 14 & 0.28 & 0.28 & 0.28 & nd & nd & $\mathrm{Nd}$ \\
\hline \multirow{6}{*}{$\begin{array}{l}\text { Drinking water } \\
\text { production }\end{array}$} & \multirow{6}{*}{5} & \multirow{6}{*}{2} & DEP & 60 & 0.76 & 0.86 & 2.17 & 2.20 & 5.91 & 9.61 \\
\hline & & & DnBP & 60 & $0.08^{\mathrm{a}}$ & 0.49 & 21.7 & 1.42 & 3.22 & 3.62 \\
\hline & & & BBP & 40 & 0.35 & 6.00 & 11.7 & 1.94 & 1.94 & 1.94 \\
\hline & & & DEHP & 80 & 0.25 & 7.41 & 383.3 & 60.2 & 63.9 & 306 \\
\hline & & & NP & 100 & 0.73 & 1.02 & 84.3 & 3.18 & 5.19 & 13.91 \\
\hline & & & OP & 0 & nd & nd & nd & nd & nd & $\mathrm{Nd}$ \\
\hline \multirow{6}{*}{ Universities } & \multirow{6}{*}{17} & \multirow{6}{*}{4} & DEP & 100 & 3.08 & 19.6 & 63.7 & 0.13 & 3.63 & 15.9 \\
\hline & & & DnBP & 94 & 0.22 & 0.66 & 3.20 & 0.51 & 1.35 & 7.46 \\
\hline & & & BBP & 94 & $0.17^{\mathrm{a}}$ & 0.31 & 11.8 & 0.41 & 0.96 & 23.0 \\
\hline & & & DEHP & 100 & 5.86 & 21.1 & 247 & 6.77 & 67.2 & 1,352 \\
\hline & & & NP & 94 & 2.07 & 8.75 & 113 & 1.53 & 14.5 & 352 \\
\hline & & & OP & 17 & 0.40 & 0.52 & 0.64 & nd & nd & $\mathrm{Nd}$ \\
\hline \multirow{6}{*}{ Domestic } & \multirow{6}{*}{45} & \multirow{6}{*}{14} & DEP & 100 & 1.82 & 10.1 & 140 & 0.41 & 1.57 & 12.3 \\
\hline & & & DnBP & 100 & 1.21 & 2.93 & 9.40 & 1.14 & 4.56 & 44.2 \\
\hline & & & BBP & 100 & 0.26 & 1.56 & 13.3 & 0.59 & 3.03 & 40.0 \\
\hline & & & DEHP & 100 & 6.71 & 40.7 & 464 & 37.4 & 117 & 403 \\
\hline & & & NP & 100 & 1.55 & 9.04 & 37.6 & 5.32 & 13.9 & 154 \\
\hline & & & OP & 69 & $0.04^{\mathrm{a}}$ & 0.89 & 3.95 & 0.22 & 0.71 & 21.0 \\
\hline \multirow{6}{*}{$\begin{array}{l}\text { WWTP } \\
\text { wastewaters }\end{array}$} & \multirow{6}{*}{24} & \multirow{6}{*}{4} & DEP & 100 & 5.23 & 9.48 & 17.7 & 0.83 & 2.82 & 24.0 \\
\hline & & & DnBP & 100 & 0.60 & 1.29 & 3.31 & 0.23 & 2.25 & 13.6 \\
\hline & & & BBP & 100 & 0.46 & 1.60 & 3.91 & 0.76 & 5.175 & 18.7 \\
\hline & & & DEHP & 100 & 39.4 & 63.0 & 160 & 153 & 238 & 760 \\
\hline & & & NP & 100 & 3.91 & 6.67 & 17.3 & 6.04 & 11.6 & 49.2 \\
\hline & & & OP & 100 & 0.49 & 1.46 & 2.97 & 0.79 & 3.10 & 8.41 \\
\hline
\end{tabular}


Table 4: Synthesis of mass fluxes of phthalates and alkylphenols within WWTP trunks

\begin{tabular}{|c|c|c|c|c|c|c|}
\hline Fluxes in kg/yr & DEP & DnBP & BBP & DEHP & NP & OP \\
\hline Min & 5,265 & 651 & 931 & 37,366 & 3,691 & 485 \\
\hline Median & 6,869 & 994 & 1,168 & 45,685 & 6,137 & 1,238 \\
\hline Mean & 7,194 & 943 & 1,226 & 56,729 & 6,549 & 1,090 \\
\hline Standard deviation & 1,854 & 176 & 256 & 25,282 & 3,140 & 437 \\
\hline Relative standard deviation (\%) & $25.8 \%$ & $18.7 \%$ & $20.9 \%$ & $44.6 \%$ & $47.9 \%$ & $40.1 \%$ \\
\hline Max & 9,663 & 1,157 & 1,656 & 103,860 & 10,562 & 1,529 \\
\hline
\end{tabular}


Table 5: Median fluxes of COD, TKN, phthalates and alkylphenols in industrial discharges (in $\mathrm{kg} / \mathrm{yr}$ )

\begin{tabular}{|l|c|c|c|c|c|c|c|c|c|}
\hline Industrial sector & $\begin{array}{c}\text { Water flow } \\
\left(\mathrm{m}^{3} / \mathrm{yr}\right)\end{array}$ & COD & TKN & DEP & DnBP & BBP & DEHP & NP & OP \\
\hline & & & & & & & & & \\
\hline & & & & & & & & & \\
\hline & & & & & & & & & \\
\hline & & & & & & & & & \\
\hline & & & & & & & & & \\
\hline Textile treatment & $1,741,811$ & 2,282 & 26.1 & 69.4 & 8.69 & 3.63 & 235 & 15.1 & 0.64 \\
\hline Pharmaceutical industries & $5,454,837$ & 3,017 & 32.7 & 18.3 & 9.03 & 4.39 & 72.4 & 18.3 & 5.46 \\
\hline Aerospace industries & 160,391 & 56.1 & 7.75 & 0.10 & 0.10 & 0.05 & 1.88 & 0.46 & 0.01 \\
\hline Garbage disposal & 842,957 & 142 & 10.2 & 3.63 & 1.17 & 0.39 & 2.17 & 1.71 & 0.45 \\
\hline Vehicle cleaning & 346,737 & 10.1 & 0.94 & 0.68 & 0.39 & 0.33 & 2.30 & 1.30 & 0.07 \\
\hline Surface treatment & 658,433 & 41.4 & 0.58 & 1.10 & 0.60 & 0.17 & 0.74 & 1.61 & 0.34 \\
\hline Metallurgy & 102,141 & 34.5 & 4.06 & 0.13 & 0.05 & 0.03 & 0.19 & 0.20 & 0.02 \\
\hline Transportation maintenance & 544,653 & 167 & 19.4 & 12.8 & 0.94 & 0.32 & 32.1 & 6.11 & 0.15 \\
\hline Drinking water production & $2,029,018$ & 10.3 & 0.61 & 1.74 & 0.99 & 12.2 & 15.0 & 2.08 & 0.41 \\
\hline Cosmetic industries & 164,757 & 297 & 30.1 & 19.0 & 0.13 & 0.01 & 7.51 & 8.98 & 0.01 \\
\hline Universities & $1,791,898$ & 951 & 188 & 35.2 & 1.83 & 0.56 & 37.8 & 16.7 & 0.93 \\
\hline $\begin{array}{l}\text { Total industrial flux after } \\
\text { adjustments }\end{array}$ & $13,837,633$ & 7,535 & 345 & 174 & 25.1 & 23.7 & 438 & 77.0 & 9.11 \\
\hline $\begin{array}{l}\text { Parisian agglomeration } \\
\text { watershed flux }\end{array}$ & $857,730,290$ & 324,212 & 43,588 & 6,869 & 994 & 1,168 & 45,685 & 6,137 & 1,238 \\
\hline Industrial contribution (\%) & $\mathbf{1 . 6}$ & $\mathbf{2 . 3}$ & $\mathbf{0 . 8}$ & $\mathbf{2 . 5}$ & $\mathbf{2 . 5}$ & $\mathbf{2 . 0}$ & $\mathbf{1 . 0}$ & $\mathbf{1 . 2}$ & $\mathbf{0 . 7}$ \\
\hline
\end{tabular}

